\title{
Study of Social Factors on Job Satisfaction of Teachers in Nahavand City
}

\section{Mohammad Khazaei}

\author{
Social Science Research and Teacher of Education in Nahavand city
}

Parang Radin

Social Science Research Mahabad city

Reza Ali Anbarlou

\begin{abstract}
Social Science Research and Teacher of Education in Tarom city Faculty of humanities sciences, Social scientists, Department of social sciences, Zanjan Branch, Islamic Azad University, Iran
\end{abstract}

\author{
Doi:10.5901/mjss.2016.v7n3s3p186
}

\begin{abstract}
This research was conducted in order to have a study of social factors on job satisfaction of teachers in Nahavand city. Also, a survey methodology and a researcher-made questionnaire with a relatively high reliability and validity were used. The spss software was used for statistical analysis; also the correlation coefficient of Pearson, the multi-variable Regression and path analysis model were used. The population in this study were 2050 teachers, 330 of whom were selected as the sample based on Cochran formula. The results indicated that there was a significant relationship between independent variables (income, relative deprivation, job satisfaction, satisfying the needs, and patterns of consumption) and the job satisfaction of teachers. Analysis model also determined that 90 percent of the variance of job satisfaction variable was explained by the independent variables.
\end{abstract}

Keywords: job satisfaction, relative deprivation, studies, income, cosumption patterns.

\section{Introduction}

Education has been taken into consideration since the early days of creation, though its importance has been acknowledged not until the past few centuries. Nowadays, education is the key to development on societies and nations' success and progress depend on the quality of education. Gholami (1998) argues that "without any doubt, the future of countries can be predicted based on the current status of education".

Dehghan (1997) claims that the importance of education can be generalized to its components. He argues that teachers are the major component of education and no country can go higher than the level of its teachers.

According to Nik Gohar (1996), if we want to have a balanced and humanistic society, we have to take teachers into special consideration. This argument points to the critical role played by teachers in the process of education, the understanding of which and valuing that refers to a concept named "job satisfaction".

Cranny (1992) believes that while many definitions have been proposed on job satisfaction and dissatisfaction, a clear and evident central point can be found in them. They define job satisfaction as "the emotional; response made by the person towards his/her job, which results from comparing one' current status in a job with what is expected from it".

Evidence shows that within our society, the status of and respect towards teachers has been declined among students' parent, people of other jobs, and common people at least for the past 50 years. That is in a way that having a pitiful view towards teachers has become a usual trend among people. Furthermore, the prospects of being a teacher is not so much acceptable for students and their parents. Top students graduated from universities prefer to be jobless rather that become teachers. In addition, some graduates who cannot find jobs in other offices reluctantly consent to be teachers.

In the current study, it has been tried to investigate the impact of such variables as the impact of consumption patterns, factors influential in the feeling of partial deprivation (comparison with intra- and inter-organizational jobs), level of education, and the impacts of Maslow's hierarchy of needs on job satisfaction among teachers. Therefore, the current study attempts to investigate factors that have effect on teachers' job satisfaction and get to significant scientific findings 
with regard to increasing their satisfaction.

According to Kalaki (1977), conducted a study investigating job satisfaction for 75 jobs in Tehran and Shiraz and found that the highest rank of job satisfaction belongs to ministers (96.4 percent) and the lowest one for servants (34 percent). With regard to teachers, high school and primary school teachers showed $\% 63.79$ and $\% 58.58$, respectively.

In a study conducted in 2002, Lee investigated the social status of teachers in Taiwan and compared that with other countries. The researcher focused on various skills and social personality of Taiwanese teachers and considered that as resulting from a multitude of factors such as manner of governance in Taiwan and its culture, politics, and history.

\subsection{Theoretical framework of the study}

According to Loke (1976), job satisfaction is a pleasing emotional state that results from the personal evaluation of one's job or one's job experience. On the other hand, job dissatisfaction is a displeasing emotional state that is created because of not being able to attain objectives.

Weiss (2002) has blended Loke's definitions of job satisfaction and dissatisfaction, therefore providing a new definition. He argues that job satisfaction is the positive or negative value judgment that a person has with regard to his/her job or status. Therefore, job satisfaction is the overall viewpoint of an individual with respect to a specific job or a status that one is satisfied from a job or has positive or negative emotions towards it. In this way, a job can both be a source of attraction or attachment (in case of attaining professional objectives and values) and a source of detachment (in case that the objectives are not attained).

Robbins (1998) argues that one of the major points in Herzberg's two-factor theory is distinguishing between two groups of motivators: hygiene factors and motivation factors. Features such as management and policies in a company, supervision, interpersonal relations, work conditions, and income have been classified by Herzberg as hygiene factors. Whenever such features are in good condition, employees will not be dissatisfied; tough they will be completely satisfied.

According to Tamin (2000), sociologists have differing views on social and economic status. For example, Marx views society in terms of economy and argues that the major reality in a society is ownership. He bases the society on ownership and places other social and cultural institutions on such base. In this regard, people in the society are divided into owners of production means and those who lack such means. On the other hand, Weber believes that economic aspect is not the only important one and adds two other aspects: power and status.

According to Gurr (1998), partial feeling of deprivation results from participants' perception of a difference existing between their value expectations and value capabilities. In his view, value expectations are conditions of life and goods that people considered themselves as being rightful for to possess, while value capabilities are goods and conditions that people think they actually have the ability to attain and maintain.

Maslow argues that needs are ordered in a hierarchical way from the most powerful to the least powerful. He has portrayed the theory in the form of a hierarchy in which, physiological needs are in the bottom, while the top level belongs to the need for self-actualization. Therefore, unless the primary needs (that are powerful) are not satisfied, higher needs would not emerge. Maslow believes that the need for self-actualization is the need for a person to be what he/she has the potential to be.

According to Bourdieu, life style can be defined as properties through the use of which, occupants of various positions distinguish themselves from others either with or without the intention of doing so. According to him, indicators of consumption (life style) include 1. Management of body, 2. Manner of shopping and purchasing goods, 3. Patterns of nutrition, 4. Free-time activities, 5. Cultural consumption.

\subsection{Hypotheses}

1. There is a significant correlation between level of education and teachers' job satisfaction.

2. There is a significant correlation between income and teachers' job satisfaction.

3. There is a significant correlation between consumption patterns (life style) and teachers' job satisfaction.

4. There is a negative correlation between feeling of partial deprivation and teachers' job satisfaction.

5. There is a significant correlation between satisfaction of needs and teachers' job satisfaction.

\section{Methodology}

With regard to its objectives and subject, the current study is a survey in which, 2050 teachers of primary, junior high, and high school have been considered as the population. Among them, 330 teachers have been chosen as the sample, 
among whom 110 people were teachers in primary schools, 110 in junior high schools, and 110 in high schools. The commonest way to come up with the sample size in simple random sampling is the use of Cochran formula, shown below (Sarayi, 2009).

$$
n=\frac{\mathrm{Nt}^{2}+\mathrm{pq}}{\mathrm{Nd}^{2}+\mathrm{t}^{2} \mathrm{pq}}=\frac{2050 \times(1.96)^{2} \times(0.25)}{2050 \times(0.05)^{2}+(1.96)^{2} \times(0.25)}=\frac{1968.82}{6.0854}=324
$$

According to the research objectives and practicality issues, in the first stage cluster sampling technique and in the second, simple random sampling technique have been applied.

In the current study, a questionnaire has been used in order to collect data. By the use of a questionnaire designed by the researcher, teachers' job satisfaction has been analyzed and SPSS software has been used for analyzing the collected data. It should be mentioned that both descriptive and inferential statistical procedures have been considered in the study. with regard to descriptive statistics, a frequency table and measures of central tendency have been applied. With regard to inferential statistics, parametric tests such as Pearson's correlation coefficient, multivariate regression, and path analysis have been used in order to test the causative-correlational relationships.

Table 1. Validity and reliability of dependent and independent variables in the study

\begin{tabular}{|l|l|c|c|c|}
\hline Variables & Type of variable & Number of items & Validity & Reliability \\
\hline Job satisfaction & Dependent & 11 & 66 percent & 71 percent \\
\hline Partial feeling of deprivaton & Independent & 6 & 77 percent & 76 percent \\
\hline Level of eduvcation & Independent & 1 & 68 percent & 72 percent \\
\hline Satisfaction of needs & Independent & 8 & 65 percent & 70 percent \\
\hline Patterns of consumption & Independent & 7 & 58 percent & 77 percent \\
\hline Income & Independent & 6 & 63 percent & 73 percent \\
\hline
\end{tabular}

Inappropriate items have been removed in order to increase the reliability of dependent and independent variables.

\section{Findings}

In descriptive statistics, we seek to generalize the findings in a specific research study to a broad population. Therefore, the first job after the collection of all relevant data is to count the number of individuals who have given special answers to each question.

Table 2. Frequency distribution of research variables

\begin{tabular}{|l|c|c|c|}
\hline Variables & Dimensions & Percentage & Freqeuncy \\
\hline high school or college diploma & 30 & 9 & 9 \\
\hline Bachelor degree & 241 & 73 & 73 \\
\hline Master's degree of higher & 59 & 18 & 18 \\
\hline Primary school teahcer & 110 & 33.33 & 33.33 \\
\hline Junior high school teacher & 110 & 33.33 & 33.33 \\
\hline High school teacher & 110 & 33.33 & 33.33 \\
\hline Income less than 1 million Tomans & 31 & 9 & 9 \\
\hline 1 to 1.5 million Tomans & 261 & 79 & 79 \\
\hline 1.5 to 2 million tomans & 27 & 8 & 8 \\
\hline More than 2 million tomans & 11 & 4 & 4 \\
\hline
\end{tabular}

The above table shows that the majority of teachers studied have bachelor degrees in their field. According to the data provided above, the number of teachers investigated in the current study are equally 110 for the three grades (primary, junior high, and high schools), equaling 33.33 of the sample. In addition, the majority of participants in the study receive 1-1.5m Tomans as monthly income.

\section{Pearson's Correlation Coefficient}

Considering that the scales in the current study are of interval type, therefore, parametric tests can be applied on them and Pearson's coefficient of correlation has been applied to test hypotheses (Ahmadi, 2011). 
Table 3. Findings of Perason's correlation coefficient between independent variables and the dependent variable of the study (job satisfaction)

\begin{tabular}{|l|c|c|}
\hline Types of variables & Pearosn's correlation & Sig. \\
\hline Level of education- job satisfaction & 0.239 & 0.000 \\
\hline Income- job satisaction & 0.431 & 0.000 \\
\hline Patterns of consumption - job satisfaction & 0.262 & 0.000 \\
\hline Partial deprivation - job satisfaction & -0.204 & 0.003 \\
\hline Satisfaction of needs- job satisfaction & 0.187 & 0.021 \\
\hline
\end{tabular}

With regard to the hypothesis 1 , the output of Pearson's correlation coefficient equals $r=0.23$ and is significant below 0.01 . Therefore, it could be argued with a 0.99 degree of certainty that the correlation between level of education and teachers' job satisfaction is significant. Hereby, the first hypothesis is confirmed.

With respect to the hypothesis 2, Pearson's correlation coefficient equals 0.43 and is significant below 0.01 . Therefore, it could be argued with 0.99 degree of certainty that the correlation between income and teachers' job satisfaction is significant.

In the hypothesis 3 , the coefficient of correlation equals $r=0.26$ and is significant below 0.01 . Therefore, with a 0.99 degree of certainty it could be argued that the correlation between patterns of consumption and teachers' job satisfaction is significant.

With regard to the hypothesis 4 , the coefficient of correlation equals $r=-0.20$ and is significant below 0.01 . Therefore, it could be argued with a 0.99 degree of certainty that the correlation between partial feeling of deprivation and teachers' job satisfaction is negatively significant. In other words, the more the feeling of deprivation among teachers, the higher would be the rate of decline on their job satisfaction (and vice versa).

With regard to hypothesis 5 , the coefficient of correlation equals $r=0.18$ and is significant below 0.05 . Therefore, it could be argued with a 0.95 degree of certainty that the correlation between the satisfaction of needs and teachers' job satisfaction is significant.

\section{5. mTest of Regression Analysis}

Table 4. regression analysis

\begin{tabular}{ccccc}
\hline Model & $\mathrm{R}$ & $\mathrm{R}$ Square & R Square & e Estimate \\
\hline 1 & $0.0526^{\mathrm{a}}$ & 0.447 & 0.356 & 3.86813 \\
\hline
\end{tabular}

a. job satisfaction

According to the analysis of regression, the multiple coefficient of correlation between teachers' job satisfaction and the linear combination of income, patterns of consumption, satisfaction of needs and feeling of deprivation is $R=0.52$ and its coefficient of determination equals $\mathrm{R}^{2}=0.44$. In other words, the ratio of variance in the dependent variable that has been predicted by the independent variables equals $\mathrm{R}^{2}=0.44$. In this analysis, the Enter technique has been applied.

Table 5. Test of regression analysis

\begin{tabular}{|l|c|c|c|c|c|}
\hline Variable & Sig. & T & Beta & SE & B \\
\hline Constant & 0.000 & 8.325 & & 2.95 & 20.7 \\
\hline Income & 0.000 & 7.632 & 0.405 & 0.157 & 1.12 \\
\hline Patterns of consumption & 0.173 & 1.463 & 0.059 & 0.038 & 0.068 \\
\hline Education & 0.000 & 6.321 & 0.257 & 0.056 & 0.328 \\
\hline Satisfaction of needs & 0.369 & 0.539 & 0.041 & 0.075 & 0.037 \\
\hline Feeling of deprivation & 0.000 & -3.612 & -0.185 & 0.045 & -0.200 \\
\hline
\end{tabular}

Dependent variable: job satisfaction

According to the above table, if the impacts of income, education, satisfaction of needs, and feeling of deprivation are kept constant, the mean score for job satisfaction equals 20.70. Therefore, one level increase or change in the income, consumption, education, satisfaction of needs, and feeling of deprivation would lead to $1.12,0.06,0.32,0.03,-0.20$ level 
increase in job satisfaction, respectively.

In addition, the standard regression function shows that income (Beta= 0.40 ) has the highest ratio in predicting job satisfaction (the deponent variable).

\section{Path Analysis}

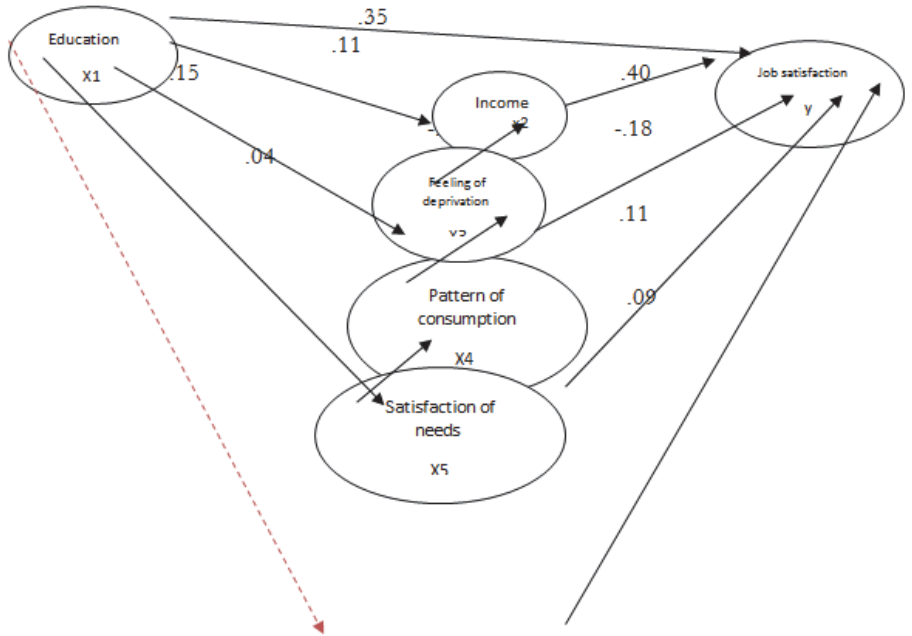

The statistical inference of variables according to the model of path analysis

According to the numbers obtained within the path analysis diagram, it could be argued that the overall impacts (direct and indirect) equals 0.69 . In addition, $e=0.31$ and $\mathrm{R}^{2}=9039$. This means that 90 percent of variance in the dependent variable has been predicted by the independent variables, while 10 percent has not been accounted for. In other words, 10 percent of the variance is related to factors other than the ones within the study.

\section{Conclusion and Suggestions}

In the current study, a significant correlation was found between the level of education and teachers' job satisfaction. In other words, valuing the variable of educational level could be helpful on teachers' job satisfaction. Nowadays. Since teachers need permission from their authorities to enroll in higher education programs, it is expected that the facilities to their education should be provided. Therefore, it could be concluded that taking the level of education among teachers into account has a significant value and teachers with higher education do show a higher rate of job satisfaction.

Another conclusion in the current study would point to the fact job satisfaction will decrease in a society if the partial feeling of deprivation among its teachers increases. According to Gurr, partial feeling of deprivation leads to dissatisfaction among people and that causes loss of dignity among people of groups.

Another conclusion is that the correlation with income and teachers" job satisfaction is significant. In other words, of teachers' possess more) income and wealth), their job satisfaction will increase.

Furthermore, it was found if the ability to make use of consumption indicators mentioned in the study increases in a society (e.g. among teachers), job satisfaction will increase there.

The final piece of conclusion reached in the study is that the correlation between satisfaction of teachers' needs in a society and their job satisfaction is significant. Maslow believes that such is the need for self-actualization- or the need for a person to be what he/she has to be. Considering the fact that job satisfaction is placed within levels 3 and 4 in Maslow's hierarchy, it is essential for teachers to satisfy their needs in level 1 and 2 in order to gain job satisfaction. Therefore, it could be concluded that the satisfaction of needs according to the hierarchy of needs would lead to increased job satisfaction. 


\section{Practical suggestions}

1. The belief that great scientific breakthroughs is the result of interaction between schools and universities (and not just universities) should be reinforced.

2. The opportunity to enroll in higher education in prestigious universities and with the minimum of costs should be provided.

3. Appropriate salary and bonuses compatible with other employees should be pain to teachers.

4. Graduates of higher education should be employed and assigned to work in primary schools (as the basis for education)

5. Appropriate and effective cooperatives specific for teachers should be developed and supported.

6. Facilities for housing and get land for construction should be provided with low costs.

7. Ministry of education should be transformed from a consumptive institution to a productive one through the establishment of banks and financial institutions.

8. Importance and holiness of teachers' role should be stressed through the provision of scenarios for movies and plays (without any prejudice)

9. Respect towards teachers should be increased within the society and the policy makers should acknowledge the fact that education has a remarkable role in the increase of national per capita GDP.

\section{Resources}

Abazari, Y., \& Chavoshiyan, H. (2002). From social class to life style. Nameh, 30.

Ahmadi, H. (n.d.). A pamphlet on advanced statistics.

Dehghan, D. (1997). A report on Bangkok international conference. Journal of the Organization of Management and Planning, 9.

Gholami, H. (2000). The current and future status of education. Tehran: Ettela'at Publications.

Gurr, T. (1998). Why men rebel. Tehran: Institute of Strategic Studies.

Kalaki, H., \& Doustdar, R. (2009). An investigation on social and professional status among the Iranian police and the effective factors. Studies in Security Management, $4 \mathrm{v}(2)$.

Lee, J. (2001). Teachers' social status in Taiwan. Tehran: Ney Publication.

Lundin, R. (1999). Theories and systems of psychology. Tehran: Virayesh Publication.

Nayeli, M. (1994). Motivation in organizations. Ahwaz: Shahid Chamran University Press.

Nik Gohar, A. (1996). Basics of sociology. Tehran: Rayzan Publishers.

Robbins, A. (1998). Organizational behavior: concepts, theories, and applications. Tehran: Center of Cultural Studies.

Sarayi, H. (2009). An overview of sampling in research studies (1st ed.). Tehran: Samt publishers.

Tamin, M. (2000). Sociology of stratification and social injustices. Tehran: Tootia Publishers.

Cranny C. J., Smith P. C., Stone E. 1992 .Job satisfaction: how people feel about their jobs and how it affects their performance 'New York: Lexington press.

Loke' E.A. (1976) the natural and causes of job satisfaction 'Chicago 'Rand' McNally

Weiss Howard. M. (2002)' deconstructing job satisfaction evaluation 'beliefs and affective experiences 'Human Resource Management Review' vol. 12. 